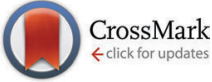

Cite this: Phys. Chem. Chem. Phys., 2016, 18, 16444

Received 4th April 2016, Accepted 23rd May 2016

DOI: $10.1039 / c 6 c p 02209 j$

www.rsc.org/pccp

\section{Efficiency and stability of spectral sensitization of boron-doped-diamond electrodes through covalent anchoring of a donor-acceptor organic chromophore (P1) †}

\author{
Hana Krysova, ${ }^{a}$ Jan Barton, ${ }^{\text {bc }}$ Vaclav Petrak, ${ }^{\text {de }}$ Radek Jurok, ${ }^{\text {fg }}$ Martin Kuchar, ${ }^{\text {fh }}$ \\ Petr Cigler*b and Ladislav Kavan*a
}

\begin{abstract}
A novel procedure is developed for chemical modification of $\mathrm{H}$-terminated $\mathrm{B}$-doped diamond surfaces with a donor- $\pi$-bridge-acceptor molecule (P1). A cathodic photocurrent near $1 \mu \mathrm{A} \mathrm{cm}{ }^{-2}$ flows under 1 Sun (AM 1.5) illumination at the interface between the diamond electrode and aqueous electrolyte solution containing dimethylviologen (electron mediator). The efficiency of this new electrode outperforms that of the non-covalently modified diamond with the same dye. The found external quantum efficiency of the P1-sensitized diamond is not far from that of the flat titania electrode sensitized by a standard organometallic dye used in solar cells. However, the P1 dye, both pure and diamond-anchored, shows significant instability during illumination by solar light. The degradation is a two-stage process in which the initially photo-generated products further decompose in complicated dark reactions. These findings need to be taken into account for optimization of organic chromophores for solar cells in general.
\end{abstract}

\section{Introduction}

Dye-sensitized solar cells (DSCs) ${ }^{1}$ usually operate with n-type semiconductor photoanodes $\left(\right.$ e.g. $\left.\mathrm{TiO}_{2}\right)$, but there are also sporadic reports on p-type DSCs with e.g. p-NiO photocathodes ${ }^{2,3}$ and on the tandem device (p,n-DSC). ${ }^{4}$ While the state-of-art n-DSC achieves a solar conversion efficiency of $14.3 \%{ }^{5}$ the p-DSCs or

\section{${ }^{a}$ J. Heyrovský Institute of Physical Chemistry, v.v.i.,}

Academy of Sciences of the Czech Republic, Dolejskova 3, 18223 Prague 8,

Czech Republic. E-mail: kavan@jh-inst.cas.cz

${ }^{b}$ Institute of Organic Chemistry and Biochemistry, v.v.i.,

Academy of Sciences of the Czech Republic, Flemingovo nam. 2,

16610 Prague 6, Czech Republic. E-mail: Cigler@uochb.cas.cz

${ }^{c}$ Faculty of Science, Charles University, Hlavova 2030, 12840 Prague 2,

Czech Republic

${ }^{d}$ Institute of Physics, v.v.i., Academy of Sciences of the Czech Republic, Na Slovance 2, 182 21, Prague 8, Czech Republic

${ }^{e}$ Czech Technical University in Prague, Faculty of Biomedical Engineering, Sitná 3105, 27201 Kladno, Czech Republic

${ }^{f}$ Forensic Laboratory of Biologically Active Substances,

University of Chemistry and Technology Prague, Technická 5,

16628 Prague 6, Czech Republic

${ }^{g}$ Department of Organic Chemistry, University of Chemistry and Technology Prague, Technická 5, Prague 6, 166 28, Czech Republic

${ }^{h}$ Department of Chemistry of Natural Compounds, University of Chemistry and Technology Prague, Technická 5, Prague 6, 166 28, Czech Republic

$\dagger$ Electronic supplementary information (ESI) available: Experimental details, XPS, HPLC, optical and Raman spectra, and additional electrochemical data. See DOI: $10.1039 / \mathrm{c} 6 \mathrm{cp} 02209 \mathrm{j}$
p,n-DSCs are still by an order of magnitude less efficient. ${ }^{2-4}$ Boron-doped diamond (BDD) is a popular electrode material in electrochemistry. ${ }^{6}$ It could be similarly attractive for the p-DSC photocathode, because it outperforms p-NiO in chemical and electrochemical stability, ${ }^{7,8}$ optical transparency ${ }^{9,10}$ and hole diffusion coefficient. ${ }^{11,12}$ However, the so far reported photoelectrochemical performance of sensitized p-BDD electrodes is not satisfactory.

Spectral sensitization of BDD by organic dyes was pioneered in 2008 by Zhong et al. ${ }^{13}$ Photocurrents of $c a .4-6 \mu \mathrm{A} \mathrm{cm}{ }^{-2}$ were observed under 1 Sun illumination in aqueous electrolyte solution with dimethylviologen acting as the electron carrier. ${ }^{10}$ Sensitization of BDD by Ru(SCN $)_{2}\left(2,2^{\prime} \text {-bipyridine, } 4,4^{\prime} \text {-dicarboxylate }\right)_{2}(\operatorname{coded} \mathbf{N} 3)^{14}$ provided photocurrents of the order of $1-10 \mathrm{nA} \mathrm{cm}^{-2}$ under 1 Sun. A biophotovoltaic variant of these systems was recently demonstrated by Caterino et al. ${ }^{15}$ using BDD with grafted bacterial photoactive centers. They observed photocurrents of about $0.3 \mu \mathrm{A} \mathrm{cm}^{-2}$ under NIR light ( $870 \mathrm{~nm}$; unspecified intensity). This photocurrent increased to $c a .2 \mu \mathrm{A} \mathrm{cm}^{-2}$ if the sensitizer loading was enhanced through a polymer brush on top of the BDD surface, but the photocurrent was quite unstable during long-term (hours) illumination. ${ }^{15}$ Yeap et al. ${ }^{16}$ modified BDD with thiophene derivatives, and observed a photocurrent of $c a$. $150 \mathrm{nA} \mathrm{cm}{ }^{-2}$ under 0.15 Sun. To enhance the dye-loading, a standard compact BDD film was replaced by a diamond foam, while ca. 3-times larger photocurrent was observed. ${ }^{17}$ It further increased to $15-22 \mu \mathrm{A} \mathrm{cm}^{-2}$ (at $1 \mathrm{Sun}$ ) during long-term illumination. 
This is the largest value for a dye-sensitized diamond, but the photo-activation is, unfortunately, associated with unclear degradation of the dye. ${ }^{17}$

The donor- $\pi$-bridge-acceptor dye, 4-(bis-4-[5-(2,2-dicyanovinyl)-thiophene-2-yl]-phenyl-amino)-benzoic acid (denoted P1, see Scheme S1 in the ESI $\dagger$ ), is one of the most efficient chromophores which is frequently used for the sensitization of $\mathrm{p}-\mathrm{NiO}^{18,19}$ and some other p-type semiconductors. ${ }^{20,21}$ In addition to applications in solar cells, the P1@NiO electrode was also successfully tested for hydrogen production by photo-electrolysis of water. ${ }^{22,23}$ Krysova et $a .^{24}$ reported on non-covalent anchoring of P1 to diamond (coated by polyethyleneimine). This electrode provided cathodic photocurrents of about $100-150 \mathrm{nA} \mathrm{cm}^{-2}$ at $0.18 \mathrm{Sun}$. The photocurrent was constant during illumination for $\mathrm{ca}$. $250 \mathrm{~s}$, but no long-term tests have been carried out yet. Here we report on an alternative strategy towards P1-sensitized diamond, leading to improved efficiency. Nevertheless, illumination of the P1 dye by 1-Sun light causes also some degradation, which is analysed here in detail.

\section{Experimental details}

\subsection{Diamond growth}

Silicon substrates $\left(5 \times 10 \mathrm{~mm}^{2}\right)$ were nucleated in an aqueous detonation nanodiamond colloid (NanoAmando, NanoCarbon Institute, nominal particle size of $4.9 \pm 0.1 \mathrm{~nm}$ ). Deposition of BDD was performed in an ASTeX 5010 (Seki Technotron, Japan) Microwave plasma enhanced chemical vapour deposition (MW PECVD) reactor with the following process parameters: $1 \%$ of methane in hydrogen, a gas pressure of $50 \mathrm{mBar}$, a microwave power of $1250 \mathrm{~W}$ and a substrate temperature of $720{ }^{\circ} \mathrm{C}$ as monitored using a Williamson Pro92 dual wavelength pyrometer. A growth time of 2 hours yielded $0.5 \mu \mathrm{m}$ thick films. Addition of trimethylboron $\left(\mathrm{B}\left(\mathrm{CH}_{3}\right)_{3}\right)$ to the gas in a $\mathrm{B} / \mathrm{C}$ ratio of $4000 \mathrm{ppm}$ during deposition translated into the $\mathrm{B}$ concentration in the bulk material of $c a .3 \times 10^{21}$ at $\mathrm{cm}^{-3}$ (ref. 25). Hydrogen termination of the surface of BDD samples was performed in hydrogen plasma using the same reactor. The hydrogenation was carried out in a hydrogen flow of $300 \mathrm{sccm}$, at a pressure of $60 \mathrm{mBar}$, and $1000 \mathrm{~W}$ microwave power for $10 \mathrm{~min}$. Samples were allowed to cool to room temperature under constant hydrogen flux.

\subsection{Syntheses}

The $\mathbf{P 1}$ dye (purity >95\%) was purchased from Dyenamo AB, Sweden. Other chemicals were supplied by Sigma-Aldrich and used as received. MilliQ water was used in all syntheses. Organic solvents were HPLC-grade and were dried before use. Sonication was performed using an Elmasonic P60 H ultrasound bath for $1 \mathrm{~min}$ at $30 \%$ power and $85 \mathrm{kHz}$. Drying was carried out under vacuum for 1 hour at $60{ }^{\circ} \mathrm{C}$, if not stated otherwise.

$\mathbf{N}$-Allyltrifluoroacetamide. To an ice-cold solution of methyl trifluoroacetate $(15.00 \mathrm{~g}, 117.1 \mathrm{mmol})$ in THF $(40 \mathrm{~mL})$ was added allylamine $(6.28 \mathrm{~g}, 110.0 \mathrm{mmol})$. The reaction mixture was allowed to warm to room temperature and stirred for 3 hours at RT.
After the mixture was concentrated under reduced pressure, the oily residue was distilled under reduced pressure, bp 70-73 ${ }^{\circ} \mathrm{C}$ (20 mbar). Yield (15.32 g, 91\%). ${ }^{1} \mathrm{H}$ NMR (300 $\mathrm{MHz}, \mathrm{CDCl}_{3}$ ): $\delta=6.38(\mathrm{~s}, 1 \mathrm{H}), 5.90-5.78(\mathrm{~m}, 1 \mathrm{H}), 5.30-5.23(\mathrm{~m}, 2 \mathrm{H}), 3.99$ $(\mathrm{t}, J=5.8 \mathrm{~Hz}, 2 \mathrm{H}) \mathrm{ppm} .{ }^{13} \mathrm{C} \mathrm{NMR}\left(75 \mathrm{MHz}, \mathrm{CDCl}_{3}\right): \delta=157.3$ (q, $J=37.0 \mathrm{~Hz}, 1 \mathrm{C}), 131.7,117.7,115.8$ (q, $J=287.0 \mathrm{~Hz}, 1 \mathrm{C})$, 42.0 ppm. IR (film, $\mathrm{cm}^{-1}$ ): 3310, 3094, 1704, 1557, 1434, 1161, 994, 931, 726. Anal. calcd for $\mathrm{C}_{5} \mathrm{H}_{6} \mathrm{~F}_{3} \mathrm{NO}$ : C 39.22; $\mathrm{H}$ 3.95; F 37.23; N 9.15. Found: C 39.83; H 3.72; F 37.02; N 9.03\%.

$\mathrm{N}$-Allyltrifluoromethanesulfonamide. Allylamine $(5.00 \mathrm{~g}$, $87.6 \mathrm{mmol}$ ) and triethylamine (10.63 g, $105.1 \mathrm{mmol})$ were mixed with $150 \mathrm{~mL}$ of chloroform at $-40{ }^{\circ} \mathrm{C}$, and trifluoromethanesulfonic anhydride ( $25.96 \mathrm{~g}, 92.0 \mathrm{mmol}$ ) was added dropwise to the mixture under a nitrogen atmosphere. The solution was stirred at room temperature for four hours. The chloroform was removed under reduced pressure and the remaining viscous liquid was dissolved in aqueous solution of $\mathrm{NaOH}(50 \mathrm{~mL}, 4 \mathrm{M})$. The aqueous solution was washed three times with $30 \mathrm{~mL}$ of chloroform. These organic phases were discarded and the aqueous solution was acidified with hydrochloric acid by weakly acidic reaction followed by washing three times with $40 \mathrm{~mL}$ of chloroform. The organic extract was dried over anhydrous $\mathrm{MgSO}_{4}$ and the solvent was removed under reduced pressure. The liquid residue was distilled twice under reduced pressure, bp 75-80 ${ }^{\circ} \mathrm{C}$ (15 mbar). Yield $14.10 \mathrm{~g}$ (85\%). ${ }^{1} \mathrm{H}$ NMR (300 MHz, $\left.\mathrm{CDCl}_{3}\right): \delta=5.81$ (ddt, $1 \mathrm{H}, \mathrm{CH}=$, $\left.{ }^{2} J=17.1,10.1,{ }^{3} J=5.6 \mathrm{~Hz}\right), 5.24\left(\mathrm{~d}, 1 \mathrm{H}\right.$, trans $\left.-\mathrm{CH}_{2}=, J=17.1 \mathrm{~Hz}\right)$, 5.15 (d, $1 \mathrm{H}$, cis- $\mathrm{CH}_{2}=, J=10.1 \mathrm{~Hz}$ ), 5.08 (brs, $1 \mathrm{H}, \mathrm{NH}$ ), 3.78 (d, $2 \mathrm{H}, \mathrm{NCH}_{2},{ }^{3} J=5.6 \mathrm{~Hz}$ ) ppm. ${ }^{13} \mathrm{C} \mathrm{NMR} \mathrm{(75} \mathrm{MHz}, \mathrm{CDCl}_{3}$ ): $\delta=132.21(=C \mathrm{H}), 119.73\left(\mathrm{q}, C \mathrm{~F}_{3}, J_{\mathrm{CF}}=320.9 \mathrm{~Hz}\right), 118.76$ $\left(=\mathrm{CH}_{2}\right), 46.64\left(\mathrm{NCH}_{2}\right)$ ppm. ${ }^{19} \mathrm{~F} \mathrm{NMR}\left(300 \mathrm{MHz}, \mathrm{CDCl}_{3}\right)$ : $\delta=-79.12$ ppm. IR (film, $\mathrm{cm}^{-1}$ ): 3310, 3180, 3094, 2888, 1721, 1648, 1440, 1372, 1261, 1231, 1151, 1072, 994, 928, 859. Anal. calcd for $\mathrm{C}_{4} \mathrm{H}_{6} \mathrm{~F}_{3} \mathrm{NO}_{2} \mathrm{~S}$ : C 25.40; H 3.20; F 30.13; N 7.40; S 16.95. Found: C 26.10; H 2.90; F 30.32; N 7.28; S $16.74 \%$.

4-(Bis-4-[5-(2,2-dicyano-vinyl)-thiophene-2-yl]-phenyl-amino)benzoyl chloride (P1-Cl). 4-(Bis-4-[5-(2,2-dicyano-vinyl)-thiophene-2yl]-phenyl-amino)-benzoic acid (P1) (75 mg, $0.124 \mathrm{mmol}$ ) was dried for $30 \mathrm{~min}$ under vacuum in a $20 \mathrm{~mL}$ dry flask using a magnetic stirrer. Under an $\mathrm{Ar}$ atmosphere, $5 \mathrm{~mL}$ of dry dichloromethane (DCM) was added, followed by triethylamine ( $43 \mu \mathrm{L}, 0.310 \mathrm{mmol}$, 2.5 eq.) and $\mathrm{SOCl}_{2}(18 \mu \mathrm{L}, 0.248 \mathrm{mmol}, 2$ eq.). The reaction mixture was stirred for 3 hours at room temperature. The solvent was evaporated and the solids were dissolved in $8 \mathrm{~mL}$ of dry THF. This dispersion was filtered using a PTFE $0.45 \mu \mathrm{m}$ filter and the solution of P1-Cl was used directly in the next reaction step for modification of 20 diamond sample plates.

\subsection{Modification of a BDD surface}

An approximately $1 \times 0.5 \mathrm{~cm}^{2}$ BDD plate was immersed in $\mathrm{N}$-allyltrifluoroacetamide or $\mathrm{N}$-allyltrifluoromethanesulfonamide in a quartz tube and secured with Ar. The plate was irradiated using a water-cooled mercury-vapor discharge lamp for 3 hours. The product was washed with methanol, sonicated and dried. For removal of the trifluoroacetyl protecting group, the plate was rinsed in $25 \%$ methanolic solution of tetramethylammonium hydroxide for 1 hour on a gel rocker, then washed with methanol, 
sonicated and dried. For removal of the trifluoromethylsulfonyl group, the plate was covered with sodium bis(2-methoxyethoxy)aluminumhydride and heated overnight at $105{ }^{\circ} \mathrm{C}$, quenched by slow addition of methanol, the newly formed precipitate was removed with $2 \mathrm{~mL}$ of $20 \% \mathrm{HCl}$, sonicated, washed with methanol, then again sonicated and dried. The dry plate was immersed in $1 \mathrm{~mL}$ of dry tetrahydrofuran (THF) containing $10 \mu \mathrm{L}$ of triethylamine. P1-Cl solution obtained in the previous step $(2 \mathrm{~mL})$ was added and left overnight at room temperature under an Ar atmosphere on a gel rocker. The plate was then washed and sonicated with THF, DCM and methanol, and finally dried. To improve the grafting conjugation yield and properties of the sensitized BDD, the acylation with P1-Cl was repeated. The plate was sonicated for 5 minutes at $100 \%$ at $37 \mathrm{kHz}$ then rinsed in a mixture of solvents (THF, DCM, and methanol) at room temperature for 3 days, washed and dried.

\subsection{Methods}

The X-ray photoelectron spectroscopy (XPS) spectra were recorded using an Omicron Nanotechnology instrument equipped with a monochromatized AlK $\alpha$ source $(1486.7 \mathrm{eV})$ and a hemispherical analyzer operating in a constant analyzer energy mode with a multichannel detector. The CasaXPS program was used for spectral analysis. Raman spectra were measured using a Renishaw InVia Raman microscope, interfaced to an Olympus microscope (objective $50 \times$ ) with an excitation wavelength of $488 \mathrm{~nm}$ and a power at the sample of $2.6 \mathrm{~mW}$. The spectrometer was calibrated by the $\mathrm{F}_{1 \mathrm{~g}}$ mode of $\mathrm{Si}$ at $520.2 \mathrm{~cm}^{-1}$. UV-Vis absorption spectra were recorded using a Perkin Elmer Lambda 1050 UV-Vis-NIR spectrometer. The solution of P1 in absolute ethanol was sealed under $c a$. 0.1 bar He into a vacuum-tight quartz optical cell (1 cm optical length).

Photoelectrochemical experiments were carried out in a onecompartment cell using a (micro-Autolab III, Metrohm) potentiostat controlled using the NOVA software. The BDD film was used as a working electrode (Ag contact with a $\mathrm{Au}$ wire insulated by TorrSeal epoxy coating), platinum was used as the counter electrode and an $\mathrm{Ag} / \mathrm{AgCl}$ electrode (sat. $\mathrm{KCl}$ ) was used as the reference electrode. The cell was equipped with a quartz optical window, and the electrode was illuminated using a white light source (Oriel Xenon lamp, model 6269) in a dark room. The solar radiation (direct and diffuse) was simulated using an Oriel AM 1.5 Global (81088) filter. The light intensity was measured using a standard Si photodiode (PV Measurements, Inc., USA). For the quantum efficiency measurements (IPCE), the light was monochromatized using a Newport 1/4 m grating monochromator (model 77200). Photoelectrochemical measurements were performed in an Ar-saturated $0.1 \mathrm{M} \mathrm{Na}_{2} \mathrm{SO}_{4}$ solution containing $5 \mathrm{mM}$ dimethylviologen $\left(\mathrm{MV}^{2+}\right), \mathrm{pH} \approx 7$. Highresolution mass spectra were measured using an LTQ Orbitrap XL (Thermo Fisher Scientific) instrument. Analysis of P1 degradation was performed on an Agilent 1260 Infinity HPLC using Luna ${ }^{\circledR}$ C8 column (Phenomenex LC $150 \times 4.6 \mathrm{~mm}$, particle size: $5 \mu \mathrm{m}$ ). Mobile phase: water (A) and acetonitrile (B), both with $0.1 \%$ trifluoroacetic acid. The linear gradient program was as follows: $0-0.5 \mathrm{~min}: 95 \%$ of $\mathrm{A}$ and $5 \%$ of $\mathrm{B} ; 16-17.5 \mathrm{~min}$ : $5 \%$ of $\mathrm{A}$ and $95 \%$ of $\mathrm{B}$.

\section{Results and discussion}

\subsection{Dye-sensitization of diamond}

Our synthetic strategy started from the hydrogen-terminated diamond surface, which was modified by photochemicallytriggered grafting of alkenes. ${ }^{26}$ Due to their direct $\mathrm{C}-\mathrm{C}$ coupling to diamond, this type of modification is known to be chemically resistant and stable. ${ }^{27}$ For instance, long chain (C10) alkenes were used for the attachment of biomolecules to diamond. ${ }^{28}$ However, long spacers are not appropriate for sensitized photoelectrodes, because the dye should be located in the closest vicinity of the surface for efficient hole-injection. Here, we used a short C3 allyl bearing a protected amino group (see Fig. 1). The linker was attached to BDD under UV illumination, followed by removal of the protecting groups which provided an aminemodified surface. Notably, the linkers are transparent at the spectral maximum of the UV lamp (254 nm) which facilitates their anchoring. Sensitization of the BDD surface was carried out by acylation of the free amines using the P1-Cl dye. As the multilayer adsorption of P1 decreases the photoelectrochemical activity, excessive dye was washed out under sonication (see the Experimental section).

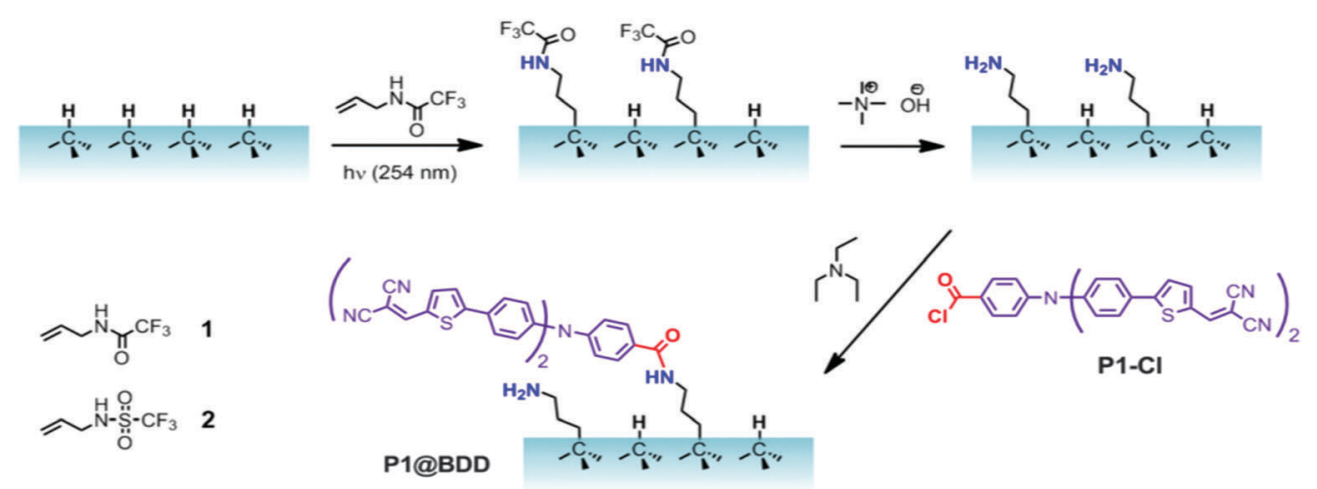

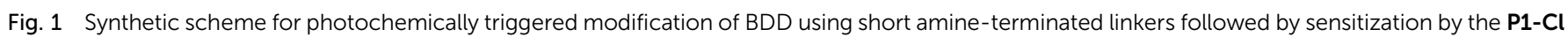
dye. Two different linkers (1 and $\mathbf{2}$ ) were used. 


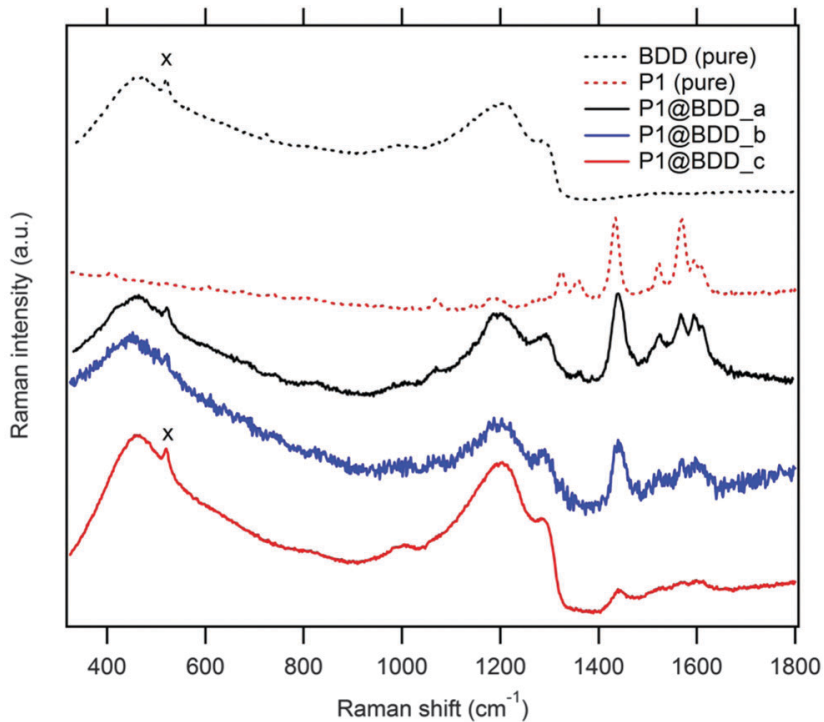

Fig. 2 Raman spectra (at $488 \mathrm{~nm}$ excitation) of pure BDD at the $\mathrm{Si}$ substrate (black dashed curve; the Si signal from the substrate at $520 \mathrm{~cm}^{-1}$ is labeled ' $x$ ') and the pure P1 dye (red dashed curve). The spectra of P1-modified BDD are shown for three samples: P1CBDD_a (black curve) is for a fresh sample; P1CBDD_b (blue curve) is for an aged sample after passing long-term photoelectrochemical tests (45 hours of chopped illumination at 1 Sun, see Section 3.2); P1@BDD_c (red curve) is for an as-received sample, which passed long-term irradiation using a $488 \mathrm{~nm}$ laser. The strong Raman intensities of $\mathbf{P} \mathbf{1}$ are ascribed to resonance enhancement, because the dye has the main optical absorption peak at the $488 \mathrm{~nm}$ wavelength (cf. Fig. 7).

The Raman spectrum of the product, P1@BDD (Fig. 2), is roughly a superposition of the spectra of pure BDD and P1, with small $\left(<7 \mathrm{~cm}^{-1}\right)$ shifts of certain modes $\left(e . g\right.$. the $1436 \mathrm{~cm}^{-1}$ line) and interestingly strong Raman intensities of the surface anchored P1 dye which are, presumably, due to resonance enhancement at the used laser line $(488 \mathrm{~nm})$. However, both P1@BDD and pure P1 decompose under the laser light (see Fig. 2 and discussion below). Photoelectron spectra (XPS; Fig. 3) provide complementary information about the surface chemistry of the products and reaction intermediates. The found surface concentration of the boron dopant decreases from $2.5 \%$ in pure BDD to $1.6 \%, 1.1 \%$ and $0.7 \%$ in the modified surfaces with linker 1, deprotected intermediate and P1@BDD, respectively (Table S2a; ESI $\dagger$ ). The attenuation of B1s to about half of its original value was observed for a monolayer of phenyl-based linker. ${ }^{16}$ Hence, we estimate a nearly monolayer coverage in our case too. This matches the earlier work by Strother $e t a l .{ }^{26}$ who reported on photochemically functionalized diamond by various long-chain alkenes under similar experimental conditions. The anchoring was reported to be covalent and unperturbed by polymerization under UV light; the surface coverage was ca. one molecule per 10 surface C-atoms, i.e. $\approx 0.3$ monolayer. $^{26}$ Deconvolution of the N1s line in our detailed XPS spectra allows distinction of two chemically-shifted species, which are tentatively assigned to the $-\mathrm{CN}$ group from the $\mathbf{P} 1$ dye and the amino groups from the linker and the triphenylamino group from the P1 dye (Table S2b and Fig. S3; ESI $\dagger$ ).

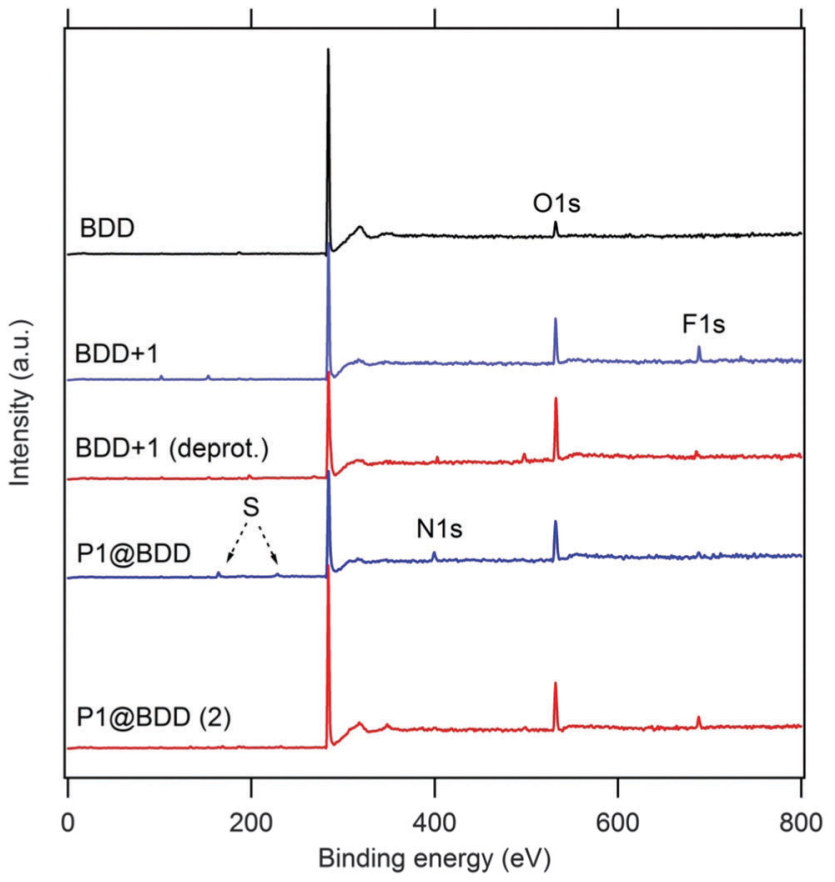

Fig. 3 XPS spectra of the studied samples. P1@BDD is the optimized sample with linker 1; P1@BDD (2) is another sample with linker 2. Curves are offset for clarity, but the intensity scale is identical for all spectra.

Because the electronic structure of the protecting group is important for the grafting yield, ${ }^{29}$ we synthesized trifluoroacetamide 1 and trifluoromethylsulfonamide 2 derivatives of allylamine (Fig. 1). Although 2 contains an excellent electron acceptor and should therefore enhance the grafting conversion, ${ }^{29}$ we observed actually a smaller photoelectrochemical activity of the sensitized BDD (see Section 3.2 and Fig. S4; ESI†). This can be explained by higher chemical stability of the protecting group, which requires harsher conditions for deprotection. In the case of a dye anchored through linker 1, the surface concentration of sulfur is diagnostic for $\mathbf{P 1}$ only. The concentration of S found by XPS ( 2.9 at $\%$; Table S2a in the ESI $\dagger$ ) is not far from 4.5 at $\% \mathrm{~S}$ which is expected for the pure $\mathbf{P 1}$ molecule (without $\mathrm{H}$-atoms). This would indicate quite high surface coverage, but the experimental error of XPS analysis and the found nonstoichiometric $\mathrm{S} / \mathrm{N}$ ratio (Table S2a in the ESI $\dagger$ ) must be also taken into account.

\subsection{Photoelectrochemical characterization}

Fig. 4 shows the response of our optimized P1@BDD electrode (linker 1) to chopped white light in an aqueous electrolyte solution with methylviologen redox mediator. The reference (non-sensitized BDD) provided small cathodic photocurrent too (ca. $20 \mathrm{nA} \mathrm{cm}{ }^{-2}$ ), which is ascribed to either $\mathrm{sp}^{2}$ impurities or specific B-states in the lattice. ${ }^{30}$ Our P1@BDD electrode exhibited a cathodic photocurrent of $c a .0 .9 \mu \mathrm{A} \mathrm{cm}{ }^{-2}$ during the first ca. 5 minutes of chopped illumination of 1 Sun intensity. (The photocurrent was proportional to the light intensity, amounting to $e . g .0 .2 \mu \mathrm{A} \mathrm{cm}^{-2}$ at 0.2 Sun for the fresh electrode).

The mechanism of photocurrent generation starts from photon absorption in P1, creating electron-hole pairs, which 


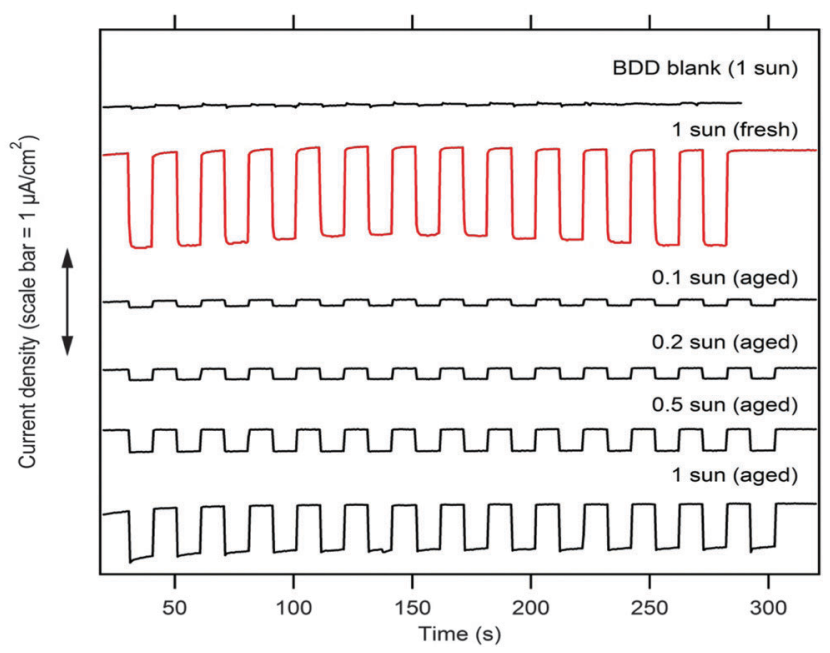

Fig. 4 Chronoamperometric plot for a blank BDD electrode and that sensitized with P1. Freshly prepared P1@BDD electrode (red curve, top) and that after passing long-term chopped irradiation (45 hour at 1 Sun). Electrolyte solution: $0.1 \mathrm{M} \mathrm{Na}_{2} \mathrm{SO}_{4}$ containing $5 \mathrm{mM}$ dimethylviologen, applied bias voltage $-0.3 \mathrm{~V}$ vs. $\mathrm{Ag} / \mathrm{AgCl}$. Illumination with simulated $\mathrm{AM} 1.5$ solar light of varying intensity. Curves are offset for clarity, but the current density scale is identical in all cases.

subsequently dissociate in the donor- $\pi$-bridge-acceptor molecular structure of P1 (Scheme S1, ESI $\dagger$ ). The separated holes are injected into the valence band of BDD, and the electrons flow to the $\mathrm{MV}^{2+}$ (dimethylviologen) electron carrier in the electrolyte solution which is finally regenerated by dark charge transfer at the counter electrode (Fig. S5, ESI $\dagger$ ). ${ }^{10,13,14,16,24}$ The HOMO level of $\mathbf{P 1}(-5.8 \mathrm{eV})^{18}$ is well below the valence band of the H-terminated diamond ( $c a .-4.2 \mathrm{eV}$ for diamond in a vacuum, and $c a .-5.5 \mathrm{eV}$ for a diamond contacting electrolyte solution). ${ }^{7}$ The LUMO level of $\mathbf{P 1}$ corresponds to a potential of $-0.87 \mathrm{~V} v s$. $\mathrm{SHE},{ }^{18}$ which is more negative compared to the $\mathrm{MV}^{2+/+}$ redox potential $(-0.45 \mathrm{~V} v$ s. SHE). Hence, both the hole injection into the $\mathrm{VB}$ of diamond and the electron transfer to $\mathrm{MV}^{2+}$ have a reasonable driving force of $c a .0 .5 \mathrm{eV}$.

The long-term stability of our P1@BDD was tested under chopped 1 Sun illumination. Interestingly, the photocurrent initially increased during $\approx 5$ hours from $1 \mu \mathrm{A} \mathrm{cm}^{-2}$ to $1.5 \mu \mathrm{A} \mathrm{cm} \mathrm{cm}^{-2}$, but then dropped to $c a .0 .6 \mu \mathrm{A} \mathrm{cm}^{-2}$ after about 40 hours (Fig. 5). These changes were further addressed by the external quantum efficiency (also called IPCE = incident photon to current conversion efficiency) $v s$. wavelength at various stages of long-term illumination. It is defined as

$$
\mathrm{IPCE}=i_{\mathrm{ph}} h v / e P=\eta_{\mathrm{inj}}\left(1-10^{-\Gamma R \varepsilon}\right)
$$

where $i_{\mathrm{ph}}$ is the photocurrent density, $h$ is Planck's constant, $v$ is the photon frequency, $P$ is the incident light power, $e$ is electron charge, $\eta_{\text {inj }}$ is the quantum yield of charge injection into the semiconductor, $\Gamma$ is the dye's surface coverage, $R$ is the electrode roughness factor and $\varepsilon$ extinction coefficient. For instance, the $\mathbf{N} 3$ dye $\left(\varepsilon_{530}=1.2710^{7} \mathrm{~cm}^{2} \mathrm{~mol}^{-1}, \Gamma \approx\right.$ 0.55 molecules $\mathrm{nm}^{-2}$ ) provides the theoretical IPCE $=0.27 \%$ on a flat surface $(R \approx 1)$ assuming $\eta_{\mathrm{inj}}=100 \%$. Experimental IPCE for a

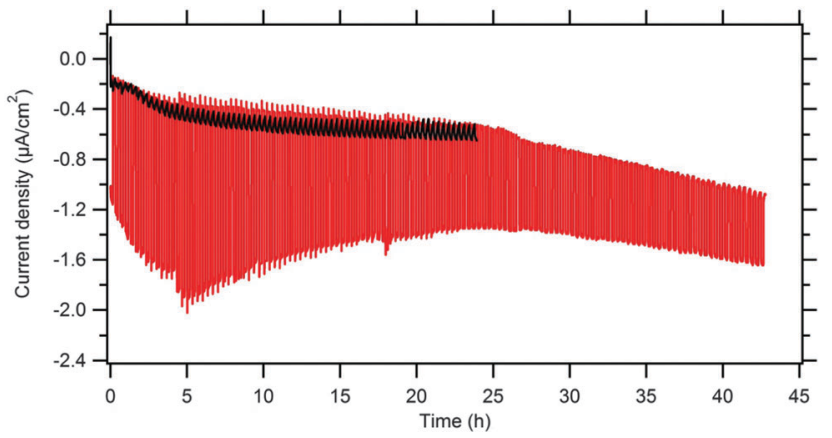

Fig. 5 Long-term chronoamperometric measurement of the diamond electrode sensitized with P1 (red curve) and the blank, non-sensitized diamond electrode (black curve). Chopped white light illumination $\left(100 \mathrm{~mW} \mathrm{~cm} \mathrm{~cm}^{-2}\right.$; simulated AM 1.5G solar spectrum, $10 \mathrm{~min}$ dark/light interval). Electrolyte solution: $5 \mathrm{mM}$ dimethylviologen in $0.1 \mathrm{M} \mathrm{Na}_{2} \mathrm{SO}_{4}, \mathrm{pH}$ 7. Applied potential bias: $-0.3 \vee v s$. Ag/AgCl.

single crystal $\mathrm{TiO}_{2}$ anatase was $0.11 \% .{ }^{31}$ Our P1@BDD shows roughly half of this value at $\lambda_{\max } \approx 350 \mathrm{~nm}$ (where the $\mathbf{P 1}$ dye has an optical peak with $\left.\varepsilon_{350}=3.47 \times 10^{7} \mathrm{~cm}^{2} \mathrm{~mol}^{-1}\right)^{19}$ and the estimated roughness factor of our BDD is $c a .4$ (ref. 17).

Our found maximum IPCE (Fig. 6) is $c a$. 4-times larger than that reported previously for a non-covalently anchored P1 to BDD. ${ }^{24}$ This confirms that the covalent anchoring is beneficial for the efficient sensitization of diamond electrodes. The blank (non-sensitized) BDD expectedly shows negligible IPCEs. The IPCEs of the $5 \mathrm{~h}$-aged electrode are similar or larger (particularly in the UV region) than those of the fresh electrode, but drop significantly for the $45 \mathrm{~h}$-aged electrode. This is qualitatively consistent with the performance under white light (Fig. 5). The IPCE maximum is blue-shifted against that of the P1-sensitized $\mathrm{p}-\mathrm{NiO},{ }^{18}$ which is reminiscent of the same spectrum of noncovalently anchored P1 to BDD. ${ }^{24}$ Our maximal photocurrent under simulated AM 1.5 solar light $\left(\approx 1.5 \mu \mathrm{A} \mathrm{cm}^{-2}\right)$ is similar or

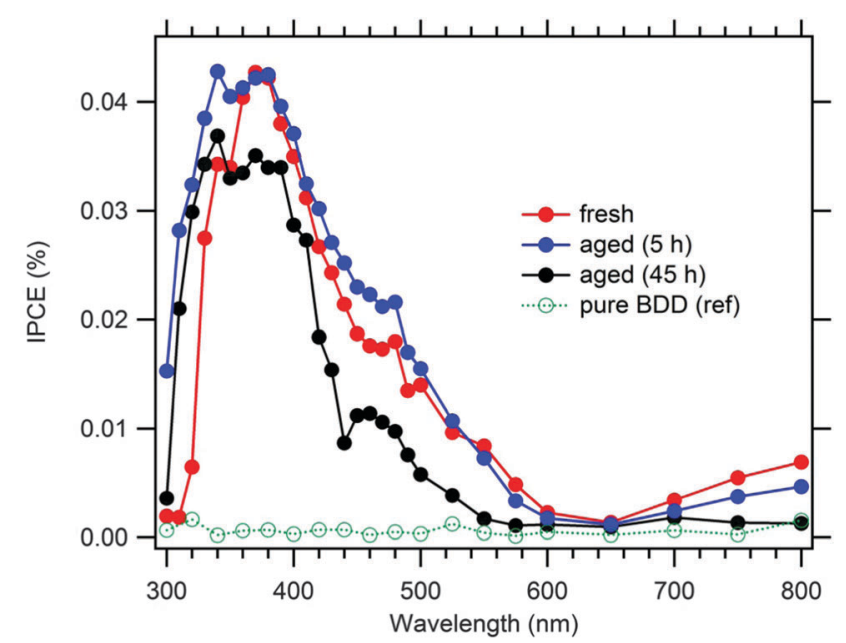

Fig. 6 IPCE spectrum for the fresh P1@BDD electrode and that after passing 4 or 45 hours of photoelectrochemical test with chopped illumination at 1 Sun (aged). A reference spectrum for pristine, non-sensitized BDD electrode is also shown. Electrolyte solution $0.1 \mathrm{M} \mathrm{Na}_{2} \mathrm{SO}_{4}+5 \mathrm{mM}$ dimethylviologen; bias voltage $-0.3 \mathrm{~V} v \mathrm{~s}$. $\mathrm{Ag} / \mathrm{AgCl}$. 
better compared to other previously reported values on flat (nontextured) BDD electrodes. ${ }^{10,13-16}$ Nevertheless, the photoelectrochemical performance of the sensitized BDD is still far from that of sensitized p-NiO, the latter exhibiting photocurrents in the $\mathrm{mA} \mathrm{cm}{ }^{-2}$ domain for good samples. ${ }^{2-4,18,19}$

\subsection{Stability of the $\mathbf{P 1}$ dye}

The Raman spectra of the photoelectrochemically treated electrode (see Section 3.2) show distinct changes resembling the photochemically degraded pure P1@BDD and solid P1, see Fig. 2 and Fig. S6 (ESI $\dagger$ ), respectively. These changes were further investigated by optical spectra and by liquid chromatography (HPLC) analysis of the degradation products in a model system, i.e. ethanolic solution of P1.

The P1 dye has two absorption maxima in tetrahydrofuran solution: ${ }^{19} 348 \mathrm{~nm}\left(\varepsilon=34720 \mathrm{M}^{-1} \mathrm{~cm}^{-1}\right)$ and $481 \mathrm{~nm}(\varepsilon=$ $57900 \mathrm{M}^{-1} \mathrm{~cm}^{-1}$ ) or $345 \mathrm{~nm}$ and $468 \mathrm{~nm}$ in acetonitrile. In ethanol, we found $349 \mathrm{~nm}\left(\varepsilon=26300 \mathrm{M}^{-1} \mathrm{~cm}^{-1}\right)$ and $488 \mathrm{~nm}$ $\left(\varepsilon=51500 \mathrm{M}^{-1} \mathrm{~cm}^{-1}\right)$. To test the photochemical stability of the ethanolic P1 solution, its spectrum was recorded after 5 and 24 hours of continuous illumination at 1 Sun in a closed, vacuum-sealed optical cell (Fig. S7; ESI $\dagger$ ). Interestingly, the Vis band bleached completely, while the UV band attenuated and blue-shifted (Fig. 7). This effect is reminiscent of the photochemical degradation of some other diamond-sensitizing dyes (thiophene-based). ${ }^{24}$

The complete decomposition of $\mathbf{P 1}$ in ethanolic solution upon 24 hours of illumination is clearly confirmed by HPLC (Fig. S8; ESI $\dagger$ ). The degradation products manifest themselves by several chromatographic peaks upon UV detection. Moreover, the irradiated solution was unstable too, and transformed during long-term (2 month) storage to more than 10 different products (Fig. S8, ESI $\dagger$ ). We attempted to analyze both mixtures using high-resolution mass spectroscopy and HPLC-MS and to resolve the mechanism of $\mathbf{P 1}$ decomposition. Unfortunately, the MS analysis did not provide reliable data for reconstruction

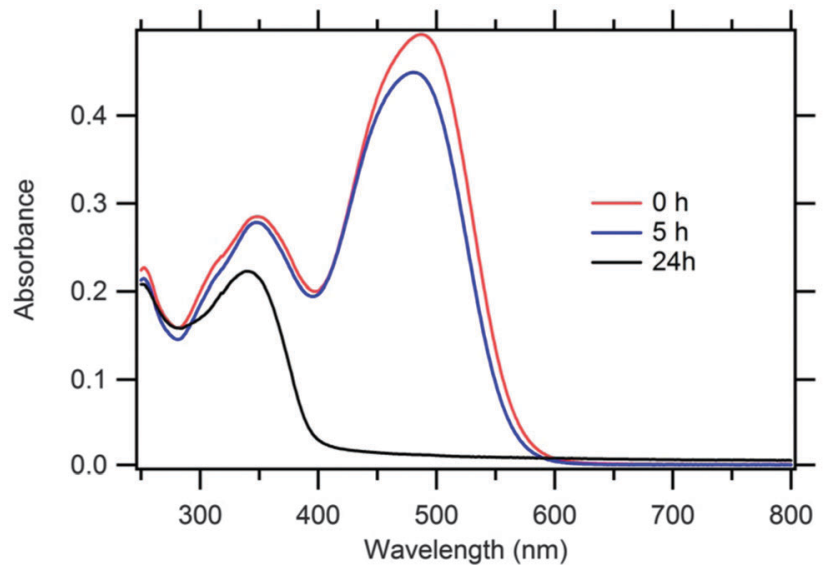

Fig. 7 UV-Vis spectrum of the solution of the P1 dye in absolute ethanol (starting concentration $10^{-5} \mathrm{~mol} \mathrm{~L}^{-1}$ ). Optical length $1 \mathrm{~cm}$. The spectrum of a fresh solution (red curve) and that after illumination with a white light of 1 Sun intensity for 5 hours (blue curve) or 24 hours (black curve). of the chemical structures. In the aged solution, we observed oligomers originating most likely from polymerization of dye fragments containing heterocyclic thiophene rings (data not provided).

Although this model experiment gave evidence of photochemical instability of $\mathbf{P 1}$ in ethanolic solution, the conditions occurring on the sensitized diamond surface can be dissimilar, and the stability of the surface-grafted dye can be better. For example, we observed a substantial photocurrent on a P1-modified diamond electrode even after $>40$ hours irradiation by chopped light at 1 Sun intensity (see Fig. 5) indicating the presence of some photoelectrochemically active dye molecules on the surface. This conclusion is also supported by Raman spectra (Fig. 2). The covalent attachment of $\mathbf{P 1}$ to the diamond surface provides obviously different electronic conditions, driving the fate of the P1 excited state (with hole injection into the diamond electrode). Furthermore, the slower diffusion of solvent molecules, impurities and radicals from the bulk solution to the interface are other possible factors contributing to better stability of the $\mathbf{P 1}$ dye on the diamond surface, as compared to its strikingly fast photochemical degradation in the solution.

For comparison, we also tested the photochemical stability of another typical dye, which is frequently used in dye-sensitized solar cells, the N719 dye: di-tetrabutylammonium cis-bis(isothiocyanato)bis(2,2'-bipyridyl-4,4'-dicarboxylato)ruthenium(II) (purchased from Dyesol, SA, Switzerland). This complex is very similar to the $\mathbf{N} 3$ dye which was also previously applied for diamond sensitization, albeit with moderate success. ${ }^{14}$ The optical spectra of $\mathbf{N 7 1 9}$ are shown in Fig. S9 (ESI $\dagger$ ). It is obvious that this dye is fairly stable in ethanolic solution under the conditions, when P1 degrades totally. Our results on N719 essentially match those of earlier studies. ${ }^{32,33}$ They found that the degradation of N719 occurred mostly through $\mathrm{S} / \mathrm{N}$ thiocyanate isomerization and through exchange of NCS ligands with e.g. solvent molecules, but without massive decomposition of the organometallic skeleton as a whole. The reported degradation products exhibited slightly blue-shifted optical bands which is in accord with our spectrum in Fig. S9 (ESI $\dagger$ ). Nevertheless, the decomposition of N719 and similar dyes like $\mathbf{N} 3$ and other organometallic complexes under the conditions of illuminated solar cells ${ }^{32,33}$ is obviously not that dramatic, like the degradation of the $\mathbf{P 1}$ dye which is studied here.

To our knowledge, there are no long-term stability tests of P1 in p-DSCs available. ${ }^{18-21}$ Photocurrent decay at a timescale of $10^{2} \mathrm{~s}$ was reported for the P1@NiO electrode during $\mathrm{H}_{2}$ generation by photo-electrolysis of water. ${ }^{22,23}$ It was ascribed to co-catalyst decomposition or to its delamination from the electrode surface. ${ }^{23}$ However, our results show that also the inherent photochemical instability of organic dyes must be considered for the design of p-DSCs and for sensitized photo-electrolytic water splitting.

\section{Conclusions}

A novel synthetic procedure is developed for covalent anchoring of a P1 dye to the surface of a H-terminated B-doped diamond electrode. The sensitized diamond electrode exhibits cathodic 
photocurrent upon illumination with solar light, which predestines it for application in p-type dye-sensitized solar cells.

The photoelectrochemical efficiency considerably outperforms that of non-covalently derivatized BDD with P1. The found external quantum efficiency (IPCE) of the P1-sensitized diamond is not far from that of the flat titania electrode sensitized by a standard $\mathrm{Ru}$-bipyridine complex, which has been frequently used in the n-type solar cells. The sensitized photocurrent is reasonably stable during ca. 40 hours of illumination at 1 Sun (AM 1.5), but there are certain photo-initiated changes of the P1 dye, both pure and diamond-anchored.

Model experiments in ethanolic solutions show that P1 is sensitive to photochemical degradation in solar light, as compared to another generic dye for solar cells, i.e. $\mathbf{N - 7 1 9}$. The former dye is totally degraded upon 24 hours of illumination in solution to more than ten (yet unidentified) products. The degradation is a two-stage process in which the initially photo-generated products further decompose in complicated dark reactions. These findings need to be taken into account for optimization of organic chromophores for solar cells in general.

\section{Acknowledgements}

This work was supported by the Czech Science Foundation, contract No. 13-31783S.

\section{References}

1 A. Hagfeldt, G. Boschloo, L. Sun, L. Kloo and H. Pettersson, Chem. Rev., 2010, 110, 6595.

2 H. Tian, J. Oscarsson, E. Gabrielsson, S. K. Eriksson, R. Lindblad, B. Xu, Y. Hao, G. Boschloo, E. M. J. Johansson, J. M. Gardner, A. Hagfeldt, H. Rensmo and L. Sun, Sci. Rep., 2014, 4, 4282.

3 S. Powar, T. Daeneke, M. T. Ma, D. Fu, N. W. Duffy, G. Goetz, M. Weidelener, A. Mishra, P. Baeuerle, L. Spiccia and U. Bach, Angew. Chem., Int. Ed., 2013, 52, 602.

4 A. Nattestad, A. J. Mozer, M. K. R. Fischer, Y. B. Cheng, A. Mishra, P. Bäuerle and U. Bach, Nat. Mater., 2010, 9, 31.

5 K. Kakiage, Y. Aoyama, T. Yano, K. Oya, J. I. Fujisawa and M. Hanaya, Chem. Commun., 2015, 51, 15894.

6 N. Yang, J. S. Foord and X. Jiang, Carbon, 2016, 99, 90.

7 A. Fujishima, Y. Einaga, T. N. Rao and D. A. Tryk, Diamond Electrochemistry, Elsevier, Tokyo, 2005.

8 L. Kavan, Z. Vlckova-Zivcova, V. Petrak, O. Frank, P. Janda, H. Tarabkova, M. Nesladek and V. Mortet, Electrochim. Acta, 2015, 179, 626.

9 C. H. Y. X. Lim, Y. L. Zhong, S. Janssens, M. Nesladek and K. P. Loh, Adv. Funct. Mater., 2010, 20, 1313.

10 Y. L. Zhong, A. Midya, Z. Ng, Z. K. Chen, M. Daenen, M. Nesladek and K. P. Loh, J. Am. Chem. Soc., 2008, 130, 17218.

11 S. D. Janssens, P. Pobedinskas, J. Vacik, V. Petrikova, B. Ruttens, J. D'Haen, M. Nesladek, K. Haenen and P. Wagner, New J. Phys., 2011, 13, 083008.
12 S. Mori, S. Fukuda, S. Sumikura, Y. Takeda, Y. Tamaki, E. Suzuki and T. Abe, J. Phys. Chem. C, 2008, 112, 16134.

13 Y. L. Zhong, K. P. Loh, A. Midya and Z. K. Chen, Chem. Mater., 2008, 20, 3137.

14 W. S. Yeap, X. Liu, D. Bevk, A. Pasquarelli, L. Lutsen, M. Fahlman, W. Maes and K. Haenen, ACS Appl. Mater. Interfaces, 2014, 6, 10322.

15 R. Caterino, R. Csiki, A. Lyuleeva, J. Pfisterer, M. Wiesinger, S. D. Janssens, K. Haenen, A. Cattani-Scholz, M. Stutzmann and J. A. Garrido, ACS Appl. Mater. Interfaces, 2015, 7, 8099.

16 W. S. Yeap, D. Bevk, X. Liu, H. Krysova, A. Pasquarelli, D. Vanderzande, L. Lutsen, L. Kavan, M. Fahlman, W. Maes and K. Haenen, RSC Adv., 2014, 4, 42044.

17 H. Krysova, L. Kavan, Z. Vlckova-Zivcova, W. S. Yeap, P. Verstappen, W. Maes, K. Haenen, F. Gao and C. E. Nebel, RSC Adv., 2015, 5, 81069.

18 P. Qin, H. Zhu, T. Edvinsson, G. Boschloo, A. Hagfeldt and L. Sun, J. Am. Chem. Soc., 2008, 130, 8570.

19 P. Qin, J. Wiberg, E. A. Gibson, M. Linder, L. Li, T. Brinck, A. Hagfeldt, B. Albinsson and L. Sun, J. Phys. Chem. C, 2010, 114, 4738.

20 X. Xu, J. Cui, J. Han, J. Zhang, Y. Zhang, L. Luan, G. Alemu, Z. Wang, Y. Shen, D. Xiong, W. Chen, Z. Wei, S. Yang, B. Hu, Y. Cheng and M. Wang, Sci. Rep., 2014, 4, 3961.1.

21 Z. Xu, D. Xiong, H. Wang, W. Zhang, X. Zeng, L. Ming, W. Chen, X. Xu, J. Cui, M. Wang, S. Powar, U. Bach and Y. B. Cheng, J. Mater. Chem. A, 2014, 2, 2968.

22 F. Li, K. Fan, B. Xu, E. Gabrielsson, Q. Daniel, L. Li and L. Sun, J. Am. Chem. Soc., 2015, 137, 9153.

23 L. Li, L. Duan, F. Wen, C. Li, M. Wang, A. Hagfeldt and L. Sun, Chem. Commun., 2012, 48, 988.

24 H. Krysova, Z. Vlckova-Zivcova, J. Barton, V. Petrak, M. Nesladek, M. Cigler and L. Kavan, Phys. Chem. Chem. Phys., 2015, 17, 1165.

25 Z. Vlckova-Zivcova, O. Frank, V. Petrak, H. Tarabkova, J. Vacik, M. Nesladek and L. Kavan, Electrochim. Acta, 2013, 87, 518.

26 T. Strother, T. Knickerbocker, J. Russell, J. E. Butler, L. M. Smith and R. J. Hamers, Langmuir, 2002, 18, 968.

27 W. Yang, O. Auciello, J. E. Butler, W. Cai, J. A. Carlisle, J. Gerbi, D. M. Gruen, T. Knickerbocker, T. L. Lasseter, J. Russell, L. M. Smith and R. J. Hamers, Nat. Mater., 2002, 1, 253.

28 A. Haertl, E. Schmich, J. A. Garrido, J. Hernando, S. C. R. Catharino, S. Walter, P. Feulner, A. Kromka, D. Steinmueller and M. Stutzmann, Nat. Mater., 2004, 3, 736.

29 X. Wang, P. E. Colavita, J. A. Streifer, J. E. Butler and R. J. Hamers, J. Phys. Chem. C, 2010, 114, 4067.

30 S. J. Green, L. S. A. Mahe, D. R. Rosseinsky and C. P. Winlove, Electrochim. Acta, 2013, 107, 111.

31 L. Kavan, M. Grätzel, S. E. Gilbert, C. Klemenz and H. J. Scheel, J. Am. Chem. Soc., 1996, 118, 6716.

32 S. M. K. Rendon, D. Mavrynsky, A. Meierjohann, A. Tiihonen, K. Miettunen, I. Asghar, J. Halme, L. Kronberg and R. Leino, Rapid Commun. Mass Spectrom., 2015, 29, 2245.

33 F. Nour-Mohhamadi, S. D. Nguyen, G. Boschloo, A. Hagfeldt and T. Lund, J. Phys. Chem. B, 2005, 109, 22413. 